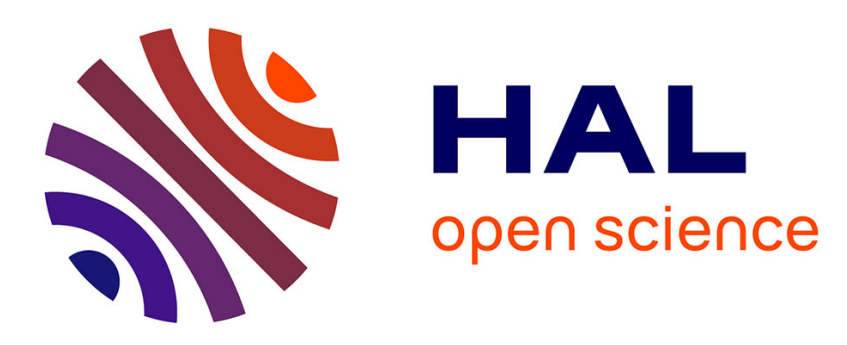

\title{
Fast-Geomimicking using chemistry in supercritical water
}

Angela Dumas, Marie Claverie, Cédric Slostowski, Guillaume Aubert, Christel Careme, Christophe Le Roux, Pierre Micoud, François Martin, Cyril Aymonier

\section{- To cite this version:}

Angela Dumas, Marie Claverie, Cédric Slostowski, Guillaume Aubert, Christel Careme, et al.. FastGeomimicking using chemistry in supercritical water. Angewandte Chemie International Edition, 2016, 55 (34), pp.9868-9871. 10.1002/anie.201604096 . hal-01360568

\section{HAL Id: hal-01360568 \\ https://hal.science/hal-01360568}

Submitted on 19 Oct 2016

HAL is a multi-disciplinary open access archive for the deposit and dissemination of scientific research documents, whether they are published or not. The documents may come from teaching and research institutions in France or abroad, or from public or private research centers.
L'archive ouverte pluridisciplinaire HAL, est destinée au dépôt et à la diffusion de documents scientifiques de niveau recherche, publiés ou non, émanant des établissements d'enseignement et de recherche français ou étrangers, des laboratoires publics ou privés. 


\title{
Fast-Geomimicking using chemistry in supercritical water
}

Dumas A., Claverie M., Slostowski C., Aubert G., Careme C., Le Roux C., Micoud P., Martin F., Aymonier C.

\begin{abstract}
:
Herein we introduce a powerful and fast method to produce nanominerals using a bottom up approach. The supercritical hydrothermal flow synthesis is exploited to produce model nanominerals by mimicking natural environments at high temperatures under pressure. This innovative concept is demonstrated with the talc synthesis; this represents a major technical breakthrough since it allows decreasing the mineral-synthesis time from tens of hours to tens of seconds. Through this example, we show these nanominerals exhibit new crystal-chemistry signals and new properties. This approach provides a means to reproduce the early stages of formation of minerals in different natural environments from sedimentary environments (low temperature and pressure) to hydrothermal/metamorphic environments (high temperature and high pressure).
\end{abstract}

The mineralogical diversity is often limited to changes in chemical composition and structure of minerals. However, particle size is a criterion to be considered since for a given mineral there are differences in physicochemical properties between micron-sized and nano-sized particles.[1,2] In nature, nano-sized minerals result from the mineral growth, mineral alteration, or mechanical grinding during tectonic events.[1] Nanominerals have long been neglected because of their small size and low crystallinity which challenged their mineral character.[3] Today, the access to advanced characterization tools that probe the structural order at the nanometer range coupled with the recent evolution of the definition of a mineral, $[3,4]$ open a new research area: the nanomineralogy. Understanding the properties of the mineral nanoparticles represents a great challenge in materials science because even in small proportion, nanominerals can induce defects of ore grade material through their reactivity. Based on the example of nano-talc, we propose a new and fast approach to mimic the first stage of mineral growth and synthesize model nanominerals for crystal chemistry analysis and the development of new materials.

Talc is a clay mineral $\left(\mathrm{Mg}_{3} \mathrm{Si}_{4} \mathrm{O}_{10}(\mathrm{OH})_{2}\right)$ which comes from the alteration of ultramafic or carbonated bedrock when exposed to hydrothermal fluids (Figure $1 \mathrm{~b}$ ). As an example, the talc deposit at Trimouns, Luzenac, in the French Pyrénées is the result of 14 million years of continuous or episodic circulation of hydrothermal fluids.[5] Medium conditions of temperature and pressure for the Trimouns deposit are estimated at $300-350^{\circ} \mathrm{C}$ and $200-300 \mathrm{MPa}$.[6, 7]

Micron-sized synthetic talc particles can be easily obtained after few months of hydrothermal synthesis in batch reactor.[8] However, by decreasing the synthesis duration to a few hours, the bottom-up approach allows control of the particle size and sub-micronic talc particles can be obtained. $[8,9]$ The possibility to finely tune particle-size and to obtain nano-sized particles was the beginning of synthetic talc material research.[10-12] The growing interest in the nano-talc particles to reinforce polymers,[13-17] to develop paints and new cosmetic formulations, pushed us to propose a novel synthesis route to meet the application challenge (Figure $1 \mathrm{c}) \cdot[18]$ 


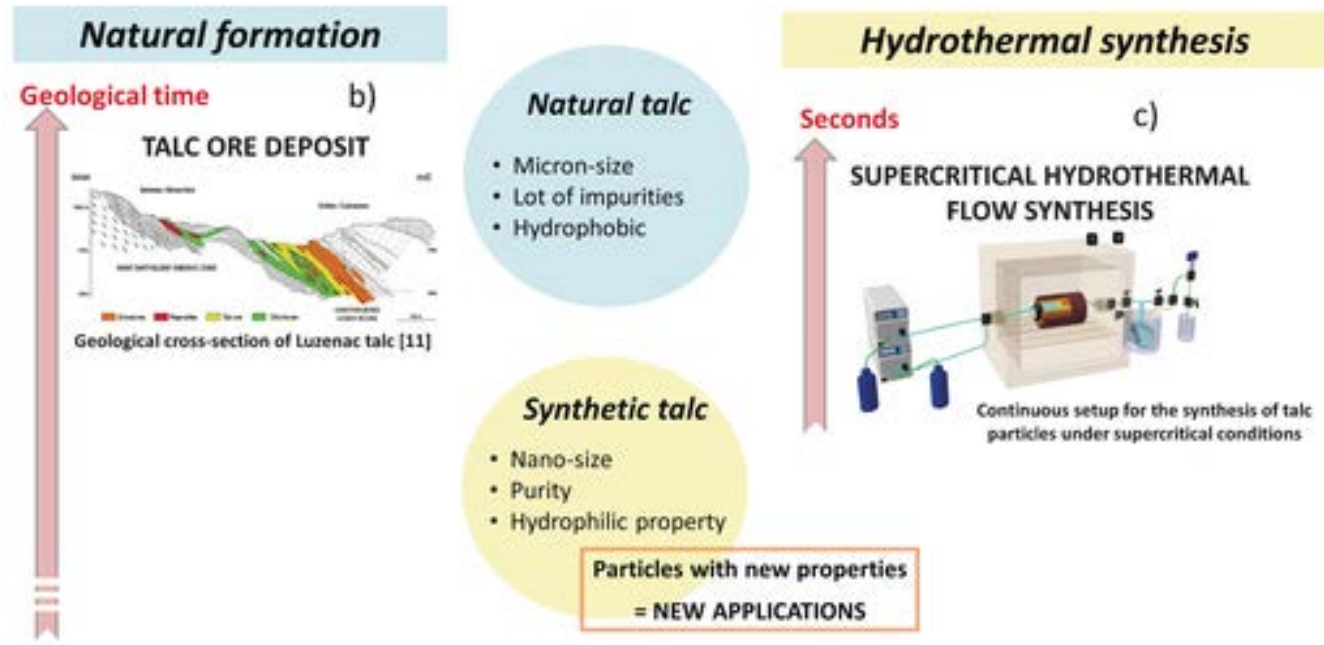

\begin{abstract}
Figure 1. a) Natural and synthetic talcs have the same crystal structure. b) Talc is a finite natural resource obtained under the action of hydrothermal fluids during several millions of years [7] and characterized by micron-sized particles. c) The supercritical hydrothermal flow synthesis is a new process to synthesize nano-sized talc particles with new properties. New synthetic talc properties open the way of new talc applications.
\end{abstract}

This synthesis process combines a continuous setup and the use of supercritical conditions to perform the supercritical hydrothermal synthesis (Figure $1 \mathrm{c}$ ).[18] A fluid is said to be supercritical when both its temperature and pressure are above its critical coordinates: in the case of water, the critical temperature is $374{ }^{\circ} \mathrm{C}$ and the critical pressure is 22.1 $\mathrm{MPa}$.[19] Above these critical conditions, water's properties change drastically. As an example, the dielectric constant is significantly reduced in supercritical conditions $\left(\epsilon \approx 6\right.$ at $400{ }^{\circ} \mathrm{C}$ and $\left.25 \mathrm{MPa}\right)$, which induces salt precipitation. [20] Water properties under supercritical conditions can be finely tuned from gas-like to liquid-like by simply adjusting the temperature and/or pressure.[21-25] Such control over the properties of the reaction medium allows controlling particle size and morphology for the synthesis of materials. $[24,25]$

To perform the talc synthesis, a mixture of sodium metasilicate at $0.04 \mathrm{~m}$ in water and a mixture of magnesium acetate at $0.03 \mathrm{~m}$ in acetic acid $(1 \mathrm{~N})$ are introduced via two separate injection lines with high-pressure pumps (JASCO PU2080, $10 \pm 0.001 \mathrm{~mL} \mathrm{~min}^{-1}$ ) and mixed at the tee mixer point. At the tee mixer point, the mixture of precursors precipitates to form the talc precursor entity and sodium acetate, which then flow into the reactor operating in supercritical conditions, where the talc crystallization occurs. The reactor is made of $1 / 8$ inch $316 \mathrm{~L}$ stainless steel coiled tubing with an internal diameter of $1.57 \mathrm{~mm}$, for a total volume of $8 \mathrm{~cm}^{3}$. The heater was a homemade coiled ceramic resistance controlling the temperature up to $500^{\circ} \mathrm{C}$. A micrometer needle valve (Autoclave Engineers) placed downstream the reactor, allows controlling the pressure in the reactor up to $40 \mathrm{MPa}$. The reaction is quenched thermally downstream with an ice bath. During the synthesis, synthetic talc is trapped in a filter while the solvent solution containing salt is recovered upon depressurization through the micrometric valve. At the end of the experiment, the filter is disassembled from the process, opened and synthetic talc is recovered.

Two sets of samples were synthesized to investigate the role of temperature and the influence of reaction time under supercritical conditions at $400^{\circ} \mathrm{C}$. Figure 2 shows the X-ray diffraction (XRD) patterns of samples obtained at $25 \mathrm{MPa}$ during about $20 \mathrm{~s}$ by varying temperature at $350^{\circ} \mathrm{C}$ (TF-35020), $380{ }^{\circ} \mathrm{C}$ (TF-38023), and $400{ }^{\circ} \mathrm{C}(\mathrm{TF}-40023)$. The samples synthesized under supercritical conditions (TF-38023 and TF-40023) exhibits the 001, 02 $\ell-11 \ell, 003$, and 06 $\ell-33 \ell$ reflections characteristic of a talc structure.[26] At lower temperature (TF-35020), 00 $\ell$ reflections of talc are almost nonexistent and only $02 \ell-11 \ell$ reflections of clays are developed. The crystallinity of the TF- 40023 sample is comparable to that of the synthetic talc sample obtained in a batch reactor during 2 hours at $300^{\circ} \mathrm{C}$ and $8.5 \mathrm{MPa}$. [8] When the reaction time is reduced by half (TF-40010), talc of lower crystallinity is obtained. These first XRD characterization results show that synthetic talc can be obtained with a continuous flow system. Very short synthesis time is required to transform amorphous talc precursors into crystalline synthetic talc. From an industrial point of view, the decrease of the synthesis 
time for the production of nano-talc from a few hours in batch reactor to few tens of second by using a continuous process represents a major technical breakthrough. Moreover, from an academic point of view, this process offers the possibility to obtain a range of nanominerals which differ by their crystallinity degree just by varying synthesis time and/or temperature (Table 1).

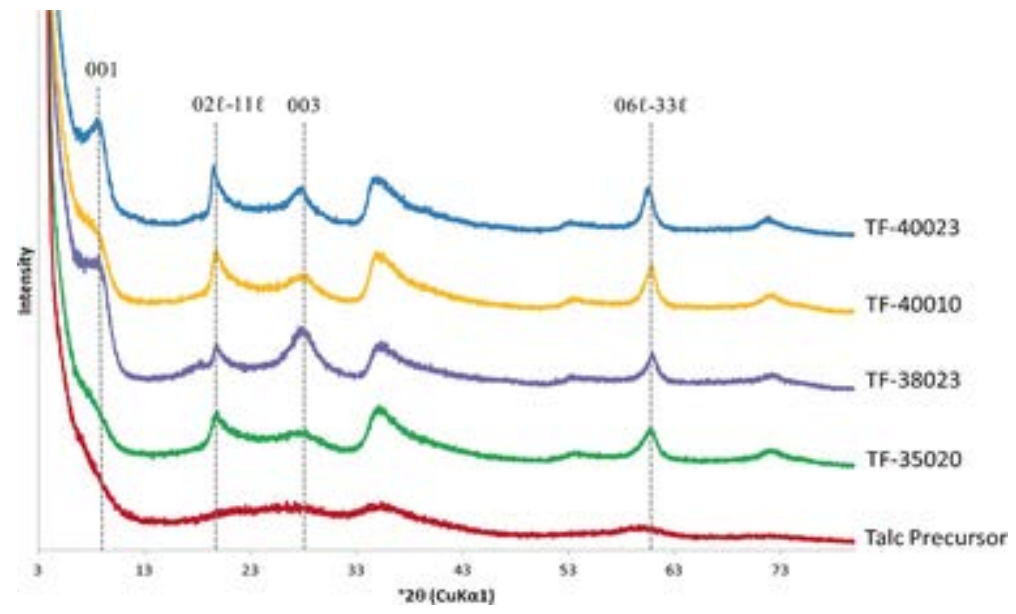

Figure 2. XRD patterns of synthetic talc samples obtained using the supercritical hydrothermal flow synthesis process. XRD patterns of samples obtained by varying temperature $\left(350,380\right.$, and $\left.400^{\circ} \mathrm{C}\right)$ or synthesis time (10 and $\left.20 \mathrm{~s}\right)$.

Table 1: Conditions of synthesis and coherent scattering domain (CSD) measurements.

\begin{tabular}{|c|c|c|c|c|c|c|}
\hline Sample & Reactor & Temperature $\left[{ }^{\circ} \mathrm{C}\right]$ & Pressure $[\mathrm{MPa}]$ & $\begin{array}{l}\text { Synthesis } \\
\text { duration [s] }\end{array}$ & $\begin{array}{l}\text { CSD c* } \\
{[\AA]}\end{array}$ & $\begin{array}{l}\text { CSD (ab) } \\
{[\AA]}\end{array}$ \\
\hline TF-35020 & \multirow{4}{*}{ Continuous } & 350 & \multirow{4}{*}{25} & & $46(1)$ & $94(2)$ \\
\hline TF-38023 & & 380 & & $20-23$ & $63(1)$ & $125(4)$ \\
\hline TF-40020 & & \multirow{2}{*}{400} & & & $92(3)$ & $174(8)$ \\
\hline TF-40010 & & & & 10 & $70(2)$ & $132(5)$ \\
\hline Talc precursor & \multicolumn{4}{|c|}{ Obtained at room temperature and ambient pressure } & \multicolumn{2}{|c|}{ amorphous } \\
\hline
\end{tabular}

The talc precursor entities, formed at the tee mixer (Figure $1 \mathrm{c}$ ), are already formed of $10 \AA$-wide tetrahedral-octahedraltetrahedral (T-O-T) arrangements. [9] Due to its numerous edges ( $\mathrm{Si}-\mathrm{O}$ and $\mathrm{Mg}-\mathrm{O}$ ) and hydroxyl groups, the talc precursors can easily form hydrogen bonds and polar interactions with water. In supercritical conditions, the drastic fall of the water density and of the dielectric constant $(\epsilon)$ restricts the solvation of particles and consequently favors the convergence and the interlocking of talc precursors. These combined effects could explain the increase of the crystal size in both the $(a b)$ plane and the $c^{*}$ direction when accessing the supercritical domain (Table 1 ).

The nanometric size of the synthetic talc particles gives them an increased number of edges which bring them, new properties for new applications, as well as spectroscopic signatures which differentiate them from natural micronic talc. Among these new properties, the hydrophilic character is the most relevant property of nano-talc because it allows it to be used as the first fluid-talc filler. In application, the use of a nano-talc gel suspension represents a significant innovation since it combines the lamellar structure of talc, which is sought for barrier properties, with a nanometric size required for a better dispersion within matrixes and a hydrophilic character that avoids the use of pre-surface coating to change the hydrophobic behavior of micro-sized talc (Figure 1).[27]

Regarding the intrinsic spectroscopic signals of nano-talc, the presence of an increased number of particle edges (Si-O and $\mathrm{Mg}-\mathrm{O}$ ), hydroxyl groups and therefore of water interaction (hydrogen bonds and polar interactions) on the particle edges modify significantly the NMR signals $\left({ }^{29} \mathrm{Si},{ }^{1} \mathrm{H}\right)$ compared to natural micron-sized talc (Figure 3 ). For example, while micronsized talc is usually characterized by ${ }^{1} \mathrm{H}$ NMR spectra with a broad band centered at $\delta=0.5 \mathrm{ppm}$ characteristic of structural 
hydrogen atoms,[28] nano-talc is characterized by 3 or 4 narrower bands at $\delta=0.4,0.8,1.8$, and 4.3 ppm corresponding to structural hydrogen atoms, magnesium hydroxyl, silanols, and physisorbed water, respectively (Figure $3 \mathrm{c}$ ).[8] The ${ }^{29} \mathrm{Si}$ NMR spectrum of nano-talc shows a band slightly shifted from $\delta=-97$ to $-96 \mathrm{ppm}$ compared to micron-sized talc and assigned to silicon atoms in a Q3 environment $(\delta=-97 \mathrm{ppm})$ and silicon atoms in a Q2 environment $(\delta=-95 \mathrm{ppm})$ located on particles edges (Figure $3 \mathrm{~d}$ ). [8] The signal at $\delta=-85 \mathrm{ppm}$ corresponds to talc precursor entities.
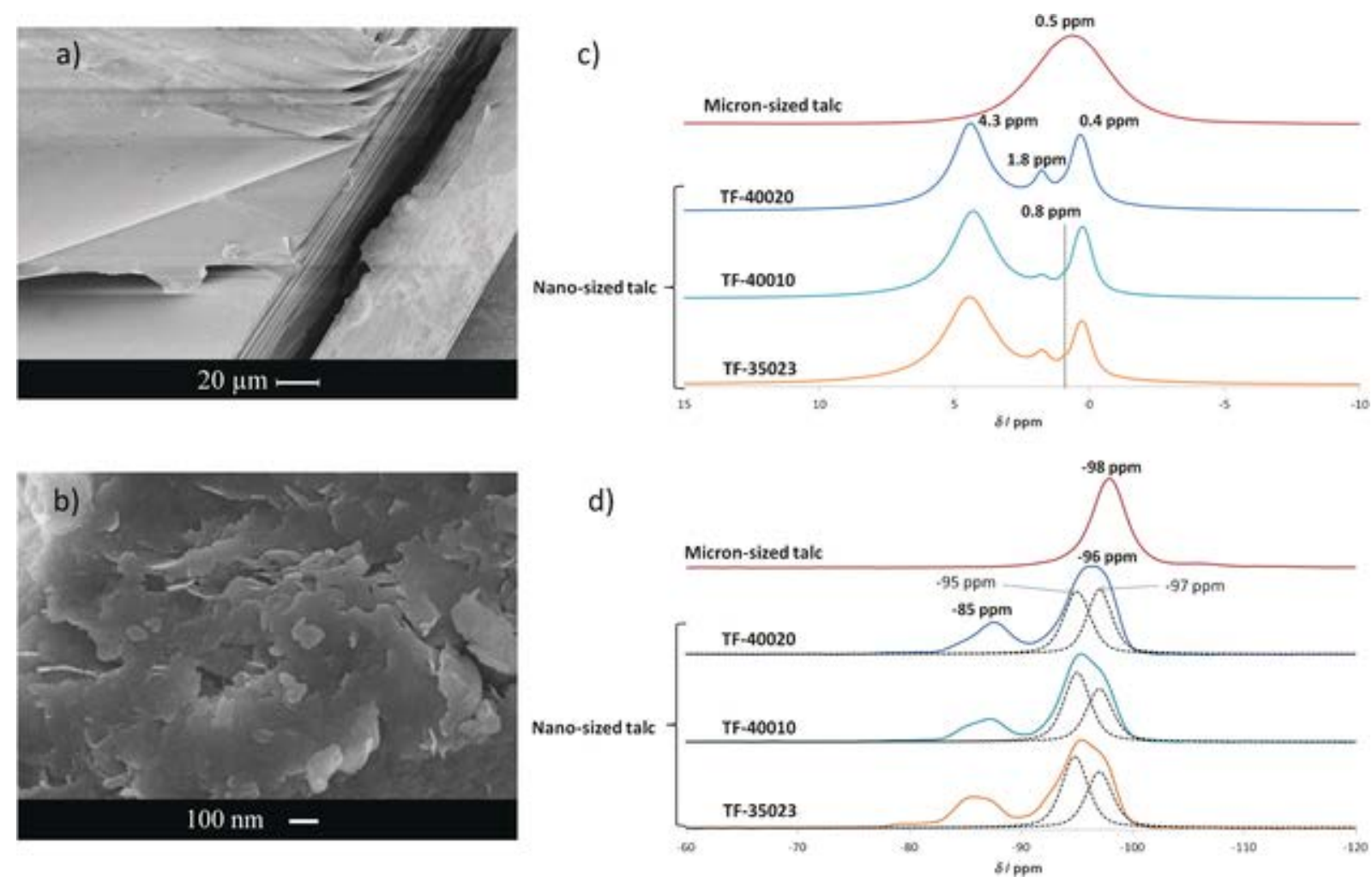

Figure 3. SEM images of a) micron-sized natural talc and b) nano-talc (TF-40020) obtained using the supercritical hydrothermal process. c) ${ }^{1} \mathrm{H} N M R$ and d) ${ }^{29}$ Si NMR spectra of synthetic and natural talc samples.

These spectroscopic signals have been recently identified in natural talc samples, pointing for the first time to the existence of a submicronic fraction in natural sample. This fine fraction is usually unconsidered in geomaterial industry since in routine analysis its signals are hidden by the ones of micron-sized particles. Nevertheless, the higher reactivity of sub-micronic particles, because of its change of behavior with water, can be responsible for ore defects. This study about nano-sized talc highlights also the potential of mineral synthesis to give a better understanding of the composition of natural samples.

The supercritical hydrothermal flow synthesis could be the basis of a synthetic-talc technology transfer because it reduces nano-talc synthesis times from a few hours in batch reactors to only few tens of seconds. This continuous supercritical hydrothermal synthesis technology, in mimicking the first stages of natural mineral growth, represents an innovative approach towards the development of geo-based advanced materials from these new geo-fillers. Compared to conventional hydrothermal synthesis methods in batch reactors, this process overcomes the rise in temperature and pressure during which mineral growth takes already place and allows a synthesis time of less than a minute. The synthetic talc produced by this process exhibits new crystal-chemistry signals and new properties compared to micron-sized natural talc. The nanoscale is responsible of its hydrophilic character making it the first fluid talc filler and opening the way of a broad range of new applications.

\section{Acknowledgements}

We acknowledge Imerys Talc Company for its financial support in the synthetic talc project. We acknowledge the Conseil Régional d'Aquitaine and the CNRS for the postdoctoral position of Angela Dumas. 
1. M. F. Hochella, S. K. Lower, P. A. Maurice, R. L. Penn, N. Sahai, D. L. Sparks, B. S. Twining, Science 2008, 319, 1631-1635.

2. G. A. Waychunas, H. Zhang, Elements 2008, 4, 381-387.

3. M. A. Caraballo, F. M. Michel, M. F. Hochella, Am. Mineral. 2015, 100, 14-25.

4. P. J. Heaney, Am. Mineral. 2015, 100, 3-3.

5. P. Boulvais, P. de Parseval, A. D'Hulst, P. Paris, Mineral. Petrol. 2006, 88, 499-526.

6. U. Schärer, P. de Parseval, Terra Nova 1999, 11, 30-37.

7. P. de Parseval, F. Fontan, F. Martin, J. Freeet, S. Y. Jiang, R. C. Wang, Acta Petrol. Sin. 2004, 20, 877-886.

8. A. Dumas, F. Martin, C. Le Roux, P. Micoud, S. Petit, E. Ferrage, J. Brendle, O. Grauby, Phys. Chem. Miner. 2013, 40, $361-373$.

9. A. Dumas, M. Mizrahi, F. Martin, F. G. Requejo, Cryst. Growth Des. 2015, 15, 5451-5463.

10. D. Arseguel, J. P. Bonino, A. Decarreau, E. Ferrage, J. Ferret, O. Grauby, C. Lèbre, F. Martin, S. Petit, WO 2008009799 A2, Jan 24, 2008, FR 2903680 B1, Oct 312008 n.d.

11. A. Dumas, F. Martin, P. Micoud, C. Le Roux, WO 2012085239 A1, June 28, 2012, FR 2969594 B1, Jan 112013 n.d.

12. A. Dumas, F. Martin, P. Micoud, C. Le Roux, WO 2013004979 A1, Jan 10, 2013, FR 2977580 B1, Aug 162013 n.d.

13. M. Yousfi, S. Livi, A. Dumas, C. Le Roux, J. Crépin-Leblond, M. Greenhill-Hooper, J. Duchet-Rumeau, J. Colloid Interface Sci. 2013, 403, 2942.

14. M. Yousfi, S. Livi, A. Dumas, J. Crépin-Leblond, M. Greenhill-Hooper, J. Duchet-Rumeau, J. Appl. Polym. Sci. 2014, 131, 40453.

15. L. M. Dos Santos, R. Ligabue, A. Dumas, C. Le Roux, P. Micoud, J.-F. Meunier, F. Martin, S. Einloft, Eur. Polym. J. $2015,69,38-49$.

16. M. A. Prado, G. Dias, C. Carone, R. Ligabue, A. Dumas, C. Le Roux, P. Micoud, F. Martin, S. Einloft, J. Appl. Polym. Sci. $2015,132,41854$.

17. M. Yousfi, S. Livi, A. Dumas, J. Crépin-Leblond, M. Greenhill-Hooper, J. Duchet-Rumeau, RSC Adv. 2015, 5, 46197-46205.

18. C. Aymonier, A. Dumas, C. Le Roux, F. Martin, P. Micoud, C. Slotowski, WO 2015159006 A1, Oct 22, 2015, FR 3019813 A1, Oct 162015 n.d.

19. A. Loppinet-Serani, C. Aymonier, F. Cansell, J. Chem. Technol. Biotechnol. 2010, 85, 583-589.

20. D. Bröll, C. Kaul, A. Krämer, P. Krammer, T. Richter, M. Jung, H. Vogel, P. Zehner, Angew. Chem. Int. Ed. 1999, 38, $2998-3014$ / Angew. Chem. 1999, 111, 3180-3196.

21. F. Cansell, C. Aymonier, A. Loppinet-Serani, Curr. Opin. Solid State Mater. Sci. 2003, 7, 331-340.

22. Y. Hakuta, H. Hayashi, K. Arai, Curr. Opin. Solid State Mater. Sci. 2003, 7, 341-351.

23. G. Galli, D. Pan, Proc. Natl. Acad. Sci. USA 2013, 110, 6250-6251.

24. C. Aymonier, A. Loppinet-Serani, H. Reverón, Y. Garrabos, F. Cansell, J. Supercrit. Fluids 2006, 38, 242-251.25H. Duan, D. Wang, Y. Li, Chem. Soc. Rev. 2015.

25. G. W. Brindley, Crystal Structure of Clay Minerals and Their X-Ray Identification: Order and Disorder in Clay Mineral Structures (Eds.: G. W. Brindley, G. Brown), 1980, Chap. 2, p. 495, The Mineralogical Society, London.

26. P. Bacchin, J.-P. Bonino, F. Martin, M. Combacau, P. Barthes, S. Petit, J. Ferret, Colloids Surf. A 2006, 272, $211-219$.

27. M. D. Alba, A. I. Becerro, M. A. Castro, A. C. Perdigón, Chem. Commun. 2000, 0, 37-38. 